\title{
Camillo Golgi (1843-1926): scientist extraordinaire and pioneer figure of modern neurology
}

\author{
Sanjib Kumar Ghosh
}

Department of Anatomy, All India Institute of Medical Sciences, Phulwarisharif, Patna, India

\begin{abstract}
Camillo Golgi was an extraordinary scientist whose contributions in the domain of neuroanatomy proved to be critical for emergence of neuroscience as a sovereign scientific discipline. Golgi's invention of the Black Reaction (La reazione nera) was a watershed event as it allowed remarkable visualization of the organizational pattern of elements of nervous system among complex puzzle of close knit interconnections. Till this time thin filamentary extensions of neural cells (axon and dendrites) could not be visualized with available staining techniques because of their slender and transparent nature. However invention of Black Reaction and its subsequent application demystified the basic architecture of brain tissue which was now visible to the scholars in all its complexity in microscopic studies. Golgi is also credited with the discovery of two types of sensory receptors in muscle tendons: Golgi tendon organ and Golgi-Mazzoni corpuscles. Golgi was the first to be successful in staining myelin component of axon, which he used to discover the myelin annular apparatus. He identified the complete life cycle of Plasmodium (malarial parasite) in human erythrocytes. His research on histological details of human kidney highlighted the existence of juxtaglomerular apparatus. Later on Spanish scientist Santiago Ramón y Cajal, based on the use of Golgi's Staining (Black Reaction) documented the morphologic details of nervous system in a more refined manner, which eventually led to the emergence of Neuron Doctrine. In recognition of their exemplary contributions in neuroscience Golgi and Cajal were jointly awarded the Nobel Prize for Physiology or Medicine in 1906.
\end{abstract}

Key words: Golgi, Black reaction, Cajal, Neurology, Neuron doctrine, Nobel prize

Received July 24, 2020; Revised August 11, 2020; Accepted September 2, 2020

\section{Introduction}

Camillo Golgi (1843-1926) was an Italian pathologist (Fig. 1) whose contributions in the domain of neuroanatomy proved to be landmark events towards the emergence of neuroscience as a discipline [1]. His discovery of the staining technique, which is known as the 'Black Reaction' ( $\mathrm{La}$ reazione nera) or Golgi's staining paved the way for microscopic visualization of the complex and intricate structural

\section{Corresponding author:}

Sanjib Kumar Ghosh (iD

Department of Anatomy, All India Institute of Medical Sciences, Phulwarisharif, Patna-801507, Bihar, India

E-mail: drsanjib79@gmail.com orientation of human nervous system [2]. His efforts were pivotal in catalysing a paradigm shift in the study of nervous system from the later part of 19th century. Till this period scholars mostly relied on observations made through experimental studies and rudimentary microscopic details (as staining technique specialized for nervous tissue was not available) for reporting findings on nervous system [3]. Consequently very little progress could be achieved regarding the details pertaining to organization of the human brain and functional aspects thereof. Golgi's work set the stage for the emergence of Neuron Doctrine/Neuron Theory which is the basis of understanding the structure and function of human nervous system in present times [4]. The significance of his discovery in the scientific domain could be judged from Golgi's own words:

"I am delighted that I have found a new reaction to demon-

\section{Copyright ( 92020 . Anatomy \& Cell Biology}

This is an Open Access article distributed under the terms of the Creative Commons Attribution Non-Commercial License (http://creativecommons.org/licenses/by-nc/4.0/) which permits unrestricted non-commercial use, distribution, and reproduction in any medium, provided the original work is properly cited. 


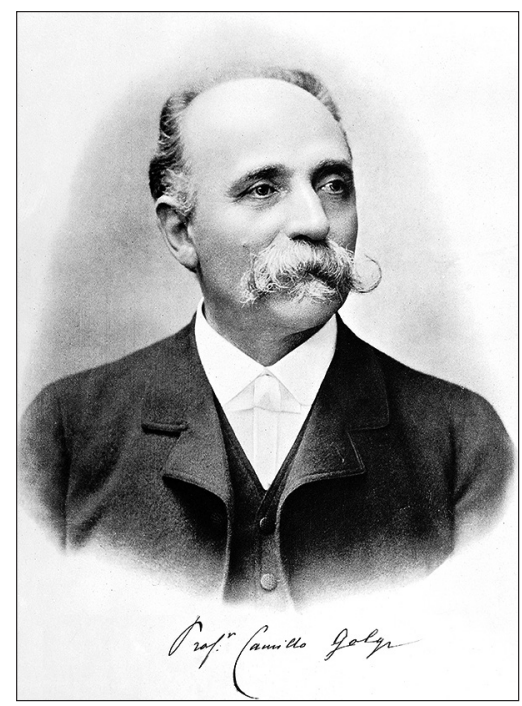

Fig. 1. A portrait of Camillo Golgi. Image in Public Domain and free from Copyright Issues. Source of Image: Wikimedia Commons.

strate even to the blind the structure of the interstitial stroma of the cerebral cortex. I let the silver nitrate react with pieces of brain hardened in potassium dichromate. I have already obtained magnificent results and hope to even better in the future" [5].

The present review was attempted to detail a brief outline of the life and achievement of this exemplary scientist who significantly contributed towards the evolution of neuroscience as a sovereign discipline. It may be opined that this review would be relevant in present times when neuroscience being empowered with the details regarding living anatomy and advances at molecular level has established itself as a prominent scientific speciality.

\section{Methods}

An extensive literature search was undertaken for this study and indexed databases such as Medline, PubMed, Scopus, EMBASE, CINAHL, Google Scholar as well as popular search platforms such as Wikipedia and standard Google search engine were referred to for relevant published materials. The following terms were used during literature search: "Camillo Golgi”, "Golgi”, "Camillo Golgi Biography”, “Golgi and Nervous System", "Golgi and Neuroanatomy", "Golgi and Anatomy", "Golgi's Staining", "Black Reaction”, "La Reazione Nera", "Neuron Doctrine", "Neuroscience in 19th Century", "Advances in Neurology" "Golgi and Staining Technique" and "Golgi and Nobel Prize". Published texts of Golgi and their translations in English were consulted from online libraries while conducting the present study and wherever applicable have been appropriately referenced. The images used in the text were procured from the internet and it was ensured that all the figures included in this study are in public domain i.e. free from copyright issues. Nevertheless the source of these images have been duly acknowledged in their respective legends.

\section{Early Life and Academic Career}

Camillo Golgi was born on 7th July, 1843 at Corteno, which is a picturesque village (in present times often referred with Golgi suffixed to its name) situated in Brescia province of Italy [6]. His father, Alessandro Golgi, was a physician who practiced in Corteno. Under his father's tutelage, Golgi studied medicine at the University of Pavia (which is close to his native village) and completed his graduation in 1865 [1]. It may be mentioned here that the University of Pavia was more than 1,000 years old (being established in the year 825 $\mathrm{AD}$ ) and was associated with famous scholars from various academic fields [7]. However Golgi had registered himself for the medicine course with the solo vision of supporting his father, who had taken great hardship to run his family [8]. However his destiny would unfold in a different manner, as he came under the influence of noted Italian psychiatrist Cesare Lombroso (1835-1909), under whose able guidance Golgi authored his dissertation for his university degree. Golgi's work was on the etiology of mental illness and being reputed for his inclination towards originality and fundamental research, Lombroso remarkably changed the academic orientation of young Golgi. Under the influence of Lombroso, Golgi started to take scholarly pursuits more seriously [9]. During this period, Golgi embarked on his studies on human brain, which was fast emerging as the most popular research area in medical domain. In academic field, human brain was previously considered as the 'seat of human soul', now with a more pragmatic approach from the academic front, it was being referred to as 'organ of human psyche' [10]. Although Lombroso was responsible for igniting the spark, pertaining to the study of brain in young Golgi's mind, however his interest in analysing brain tissue under microscope (which eventually earned Golgi the Nobel Prize) was aroused by Italian physician Giulio Bizzozero (1846-1901). Bizzozero was a noted exponent of the use of microscopic studies (microscope was an extremely popular scientific instrument in 
those days due to emergence of advanced histological preparation methods) for exploring the truth within the domain of medical science [11]. It would be a prudent statement that Golgi's career was shaped by the works of two extraordinary scientists, whom he came across during his formative years in academics. Lombroso introduced Golgi to the study of human nervous system and Bizzozero guided him towards the histological studies of human brain.

\section{Orientation Towards Research in Neurology}

Being spurred by the academic flair of his mentor Bizzozero, Golgi dedicated himself to scientific exploits in the field of histopathology. Between the period of 1870 and 1872 , he published his noteworthy findings on the structure of neuroglia, which were appreciated within the scientific fraternity and widely cited in periodicals. However in spite of his rise in the academic front, he was not offered any professional position in the University of Pavia [12]. Moreover, most of his meagre earnings were spent towards expenditures incurred in publishing his works. Subsequently, his father Alessandro urged upon him to search for a better position elsewhere [6]. Hence by unfortunate turn of events, Golgi had to leave his academic passion for financial security at this point of time. On 1st June, 1872, he entered into medical service and joined as the Chief Physician at Pio Luogo degli Incurabili at Abbiategrasso, Italy. However as an ardent acolyte of mother science, he refused to part with his passion for academic research [13]. As a testimony of his steely resolve, the devotion towards pursuit of knowledge, which was ignited in his mind by his luminary mentors in Pavia, never got snuffed out in the face of adversities. Although scope and facilities for research were much limited in his new position, however Golgi could overcome all these by setting a laboratory of his own with rudimentary facilities in the kitchen of his apartment [1]. It was in this small set up, Golgi invented the 'Black Reaction' (Golgi's staining) which was to revolutionize the science of neurology and the way we know the nervous system in present day [14]. This memorable event catapulted Golgi to academic prominence and he was appointed as the Professor of Histology in his alma mater, University of Pavia in 1876. In 1879, he became the Professor of General Pathology and the honorary chief of the medical hospital in Pavia [15]. Being empowered by his own invented technique, Golgi continued with his research in the field of nervous system and documented many hitherto unknown details. In
1893, Golgi was appointed as the Rector of the University of Pavia and held the position till 1896. In following years, he ventured into other areas of research pertaining to medical science [16]. He reached the pinnacle of his professional career in 1906, when he shared the Nobel Prize for Physiology or Medicine with Spanish scientist Santiago Ramón y Cajal, whose remarkable contributions in the field of neuroscience shaped the Neuron Doctrine/Neuron Theory [17]. During his lifetime, Golgi served as honorary advisor in the Universities of Cambridge, Geneva, Oslo, Athens and Paris. He also held the prestigious position of Dean of Medical Faculty in the University of Pavia. He also served as a member of a number of International Scientific Academies and Societies. He served as the Director of the Military Hospital in Pavia during the First World War [15]. He retired from his position in the University of Pavia in 1918, however he remained as the Professor Emeritus there. Golgi's last years before his death in Pavia, on 21st January, 1926, were mostly devoted towards his resistance for establishing a University in Milan, which in his opinion would have curtailed the importance of his alma mater, University of Pavia (as they were very close in terms of distance) which understandably was very close to his heart as he had served as he had served almost his entire professional life there [12].

\section{Invention of the Black Reaction}

Golgi's invention of the Black Reaction (La reazione nera) was a watershed event towards the emergence of neuroscience in the academic domain [18]. The invention of this histological breakthrough epitomises Golgi's stubborn desire for scientific research. It is also a precedent when the sacred pyre of science overcame the earthly obstacles. Till this time, histological studies of human brain tissue met with little success even though advances in staining techniques produced remarkable results pertaining to tissues elsewhere in the human body [19]. This can be primarily attributed to the fact that the cells in nervous tissue are densely packed and consequently very little information on their structure and organization (interconnections) could be ascertained under the microscope if all the cells are stained. Moreover the thin filamentary extensions of neural cells (axon and dendrites) could not be visualized with available staining techniques because of their slender and transparent nature [20]. It was under such a scenario that the Black Reaction was invented by Golgi. In this technique, pieces of brain tissue are first 
of all fixed in aldehyde and then kept in solution of potassium dichromate. After this silver nitrate is allowed to react with these brain tissues hardened in potassium dichromate. The cells in the brain tissue thus stained are filled by microcrystallization of silver chromate. The chief advantage of this technique is that for unknown reasons, the silver chromate precipitate randomly stains only $1 \%$ to $5 \%$ of the cells in black with total sparing of the remaining cell population in the tissue. Such a phenomenon remarkably allows visualization of the organizational pattern of elements of nervous system among the complex puzzle of close knit interconnections (Fig. 2). This technique was initially named as 'Black Reaction' or 'La Reazione Nera' by Golgi. However later on it was identified as a unique chemical-biological phenomenon and hence came to be known as 'Golgi's impregnation' or 'Golgi's staining'. Golgi published the first picture of nerve tissue stained with his technique in 1873 , which illustrated the whole nerve cell, including its cell body, axon and branching dendrites (Fig. 3) [21, 22].

The invention of Golgi's staining demystified the basic architecture of brain tissue which was now visible to the scholars in all its complexity in microscopic studies. Initially Golgi concentrated on unravelling the morphology of cerebral cortex through his new found technique, however over a period of time he documented details pertaining to other areas of the human brain. These details complimented with relevant illustrations were first serially published in order of discovery in Rivista sperimentale di Freniatria e Medicina Legale and eventually compiled as single volume collection [23].

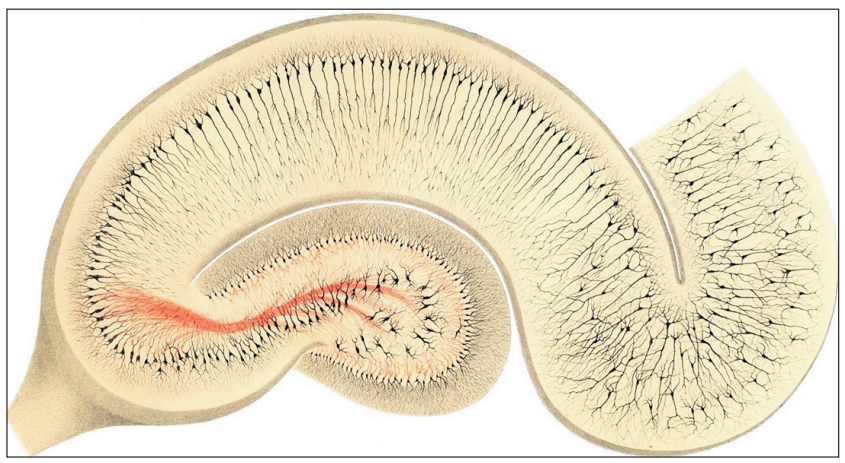

Fig. 2. Figure showing microscopic picture of hippocampus stained with Black Reaction or Golgi's Staining Technique. Histological plate prepared by Golgi himself. Image in Public Domain and free from Copyright Issues. Source of Image: Wikimedia Commons.

\section{Other Scientific Discoveries by Golgi}

After assuming charge as the Professor of Histology in Pavia, Golgi devoted himself to academic research with renewed enthusiasm. In 1878, he described two types of sensory receptors in muscle tendons: Golgi tendon organ and Golgi-Mazzoni corpuscles [24]. The Golgi tendon organ is a proprioceptive receptor (proprioceptor) which is located in the muscle tendons. In case of increased muscle tension, the receptor inhibits further muscle contraction and thus protects against muscle damage. Golgi-Mazzoni corpuscles are pressure receptors (pressoceptors) which encapsulates the sensory nerve endings in the subcutaneous tissue of fingertips. In 1879, Golgi invented another staining method with potassium dichromate and mercuric chloride, which was a corollary of his famed Black Reaction. This staining technique was specifically aimed at staining the myelin component of axon. Using this reaction, Golgi discovered the myelin annular apparatus which is also referred to as 'horny funnel of Golgi-Rezzonico' [25,26]. After 1879, when Golgi became Professor of General Pathology and assumed the charge of medical hospital in Pavia, his focus area in research changed to pathogenesis of malaria. He started to correlate the developmental stages of the parasite in human blood (pathological analysis) with the clinical picture in patients. In this way he identified the complete life cycle of Plasmo-

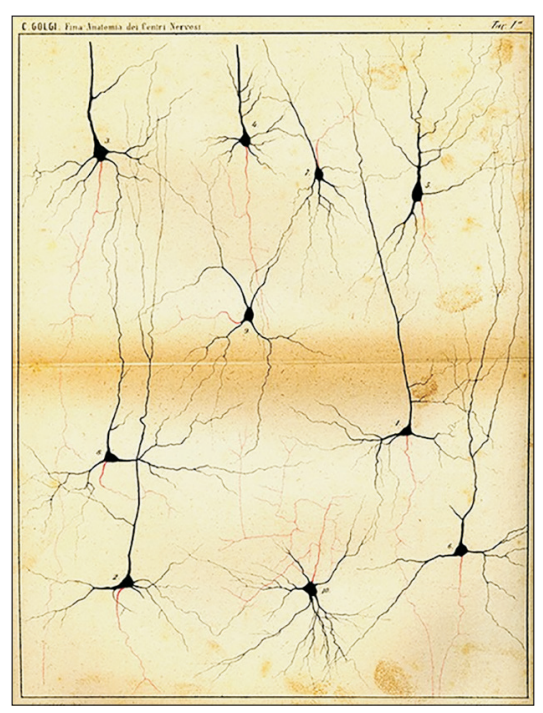

Fig. 3. Figure showing nerve cell stained with Black Reaction or Golgi's Staining Technique. Histological plate prepared by Golgi himself. Image in Public Domain and free from Copyright Issues. Source of Image: Wikimedia Commons. 
dium (malarial parasite) in human erythrocyte, which is eponymous as Golgi cycle. He also discovered the cardinal correlation between the segmentation of malarial parasite in human blood (pathological phenomenon) with the occurrence of febrile bouts in patients [27].

From 1887 onwards, Golgi again focussed on histological studies and discovered the temporal relation between the vascular pole of glomerulus in kidney and distal tubule, which eventually came to be known as the site of formation of Juxtaglomerular Apparatus. Golgi observed that although the loops of Henle were situated in the renal medulla, however the terminal part of ascending loop (from where the distal renal tubule emerges) invariably enters the renal cortex and comes to lie in close relationship with the vascular pole of the renal glomerulus $[28,29]$. Later on this area was christened as the Juxtaglomerular Apparatus, which plays a significant role in blood pressure regulation. The portion of the distal tubule which lies at the vicinity of vascular pole (as observed by Golgi) forms specialized epithelial cells (macula densa), which in response to elevated sodium levels trigger contraction of afferent arteriole thus reducing blood flow to the glomerulus. The Juxtaglomerular Cells of afferent arteriole then secretes Renin (local hormone) which regulates blood pressure through Renin-Angiotensin pathway.

In 1893, Golgi discovered the extensive canalicular network of parietal cells of the gastric glands of stomach,

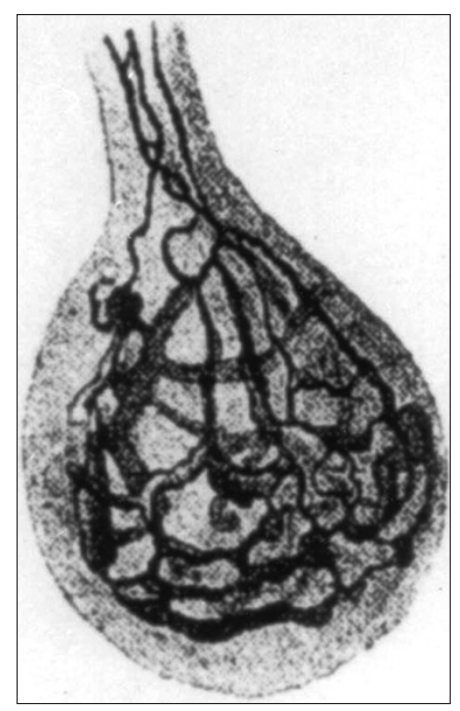

Fig. 4. Figure showing the Golgi's Apparatus. This was the first picture of the scientific entity which was published by Golgi himself. Image in Public Domain and free from Copyright Issues. Source of Image: Wikimedia Commons. through which secretions of these cells (hydrochloric acid/ HCL) are transported [30]. After a short administrative hiatus as the Rector of the University of Pavia, Golgi once again turned his attention towards research on nerve tissue based on the use of 'Black Reaction'. In 1897, he reported the presence of a 'reticular apparatus' in the cytoplasm of spinal ganglia cells (Fig. 4) [31]. He observed that this particular entity was autonomous of the nucleus and cell membrane. However through further research (undertaken by his contemporaries in Pavia) it became evident, that this structure was not exclusive of nerve cells, and was ubiquitous in eukaryotic cells. In present times, this cellular entity is referred to as 'Golgi apparatus' or 'Golgi body' [2,32]. All of Golgi's published literature were compiled as Opera Omnia, which was published from Milan. The first three volumes of Opera Omnia were published in 1903 (Fig. 5). However the final volume was published posthumously in 1929 and was edited by his colleagues in Pavia [33].

\section{Controversy Regarding the Neuron Doctrine}

During the last decade of 19th century and the first of 20th century, Camillo Golgi and his contemporary Spanish scientist Santiago Ramón y Cajal were involved in a strong debate with regards to the basic architecture and organization of the nervous system [34]. Golgi had proposed the "dif-

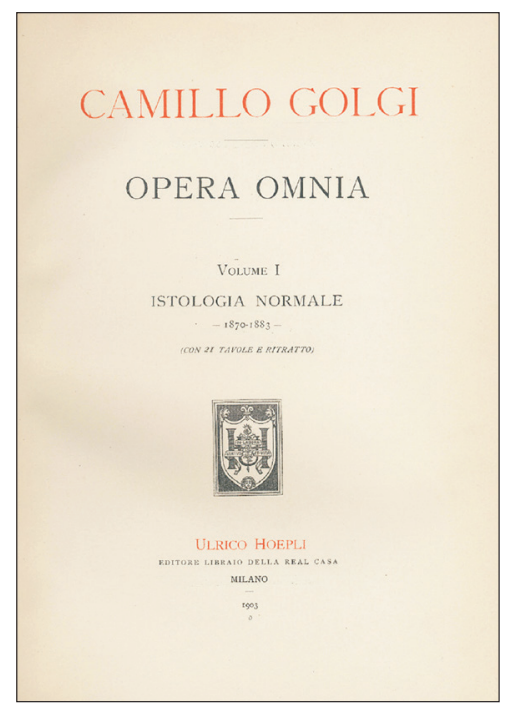

Fig. 5. Figure showing the Cover Page of the First Volume of Opera Omnia (Collections of Published Documents of Camillo Golgi) which was published in 1903. Image in Public Domain and free from Copyright Issues. Source of Image: Wikimedia Commons. 
fuse nervous net" theory based on this findings. According to this theory the axons and the dendrites are all connected in a diffuse network, which constitutes the nervous system. Thereby in Golgi's opinion, the entire nervous system essentially comprises of a magnum communication network irrespective of the presence of individual organs [35]. This theory implied that conduction of nerve impulse is chaotic in nature and could travel diffusely as well as to and fro. However since this is not the case, hence researchers envisioned an alternate theory. Among them, the pioneering concept was proposed by Cajal in 1894 while delivering a lecture at the Royal Society of London. Cajal used Golgi's staining technique but was able to visualize the morphologic details of nervous system in a more refined manner. Cajal illustrated the entire structure of nerve cells, starting from the tips of dendritic branches right up to the tapering ends of axons. Thus he proposed the 'Neuron Doctrine' or the 'Neuron Theory' whereby the neuron forms the basic anatomical and physiological unit of nervous system, which could explain the functional organization of the nervous system [36,37].

The entire academic community pertaining to neuroscience were embroiled in this ongoing debate as they got themselves aligned in a polarized scenario. One camp was referred to as 'the reticulists' and were led by Golgi himself and the other camp was christened as 'the neuronists', who were strong proponents of the theory proposed by Cajal [38]. In due course of time and with availability of more in-depth research findings, the 'Neuron Doctrine' started making deep inroads and eventually got firmly established as the basis of neuroscience [39]. Nevertheless, there is no denying the fact that it was the invention of 'Black Reaction' by Golgi which formed the core element for the emergence of 'Neuron Doctrine'.

\section{Being Honored with the Nobel Prize}

In recognition of their exemplary works in the field of neuroscience, Camillo Golgi and Santiago Ramón y Cajal were jointly awarded the Nobel Prize for Physiology or Medicine in 1906 [40]. As per the Nobel citation, Golgi and Cajal were honoured "in recognition of their work on the structure of the nervous system". Golgi's name was proposed for the Nobel Prize in 1906 by four standalone scholars: Oscar Hertwig, Professor of Comparative Anatomy from Berlin; Albert Kölliker, Professor of Anatomy from Würzburg; Gustaf Retzius, former Professor of anatomy from Stockholm and Carl Magnus Fürst, Professor of Anatomy from Lund [40]. The prize ceremony was held at the Great Hall of the Royal Academy of Music, Sweden, on the 10th of December, 1906, which is the death anniversary of Alfred Nobel. The following day, Golgi delivered the Nobel Lecture (in French) which was titled, "La Doctrine du Neurone" or "The Neuron Doctrine" [41]. Although Golgi elaborated on the theory and facts in the context of Neuron Doctrine, however his choice of the topic was quite ironical as the title of his lecture was the very theory proposed by his scholarly adversary Cajal and which was opposite to Golgi's own viewpoint [42].

\section{Conclusion}

Camillo Golgi was an extraordinary scientist who was blessed with enduring vigour for academic research. $\mathrm{He}$ served mother science with utmost passion and unravelled the scientific details hitherto unknown from mankind as an ardent explorer. His invention of the "Black Reaction" (La Reazione Nera) was the most significant event in the context of neuroscience in 19th century. His scientific exploits set the tone for further research in neurology by his contemporaries and future scholars. In modern times, when neuroscience has achieved great heights and novel findings are reported on a regular basis [43], it would be prudent to respectfully remember the person who laid the foundation of this scientific discipline.

\section{ORCID}

Sanjib Kumar Ghosh:

https://orcid.org/0000-0002-7293-6735

\section{Author Contributions}

Conceptualization: SKG. Data acquisition: SKG. Data analysis or interpretation: SKG. Drafting of the manuscript: SKG. Critical revision of the manuscript: SKG. Approval of the final version of the manuscript: all authors.

\section{Conflicts of Interest}

No potential conflict of interest relevant to this article was reported. 


\section{Acknowledgements}

The authors express heartfelt gratitude to all the residents and faculty members of the Department of Anatomy, All India Institute of Medical Sciences, Phulwarisharif, Patna, India for their unconditional support throughout the study. We are grateful to the authorities of All India Institute of Medical Sciences, Phulwarisharif, Patna, India for their kind cooperation during the course of this study.

\section{References}

1. Mazzarello P. Camillo Golgi's scientific biography. J Hist Neurosci 1999;8:121-31.

2. Friend DS, Murray MJ. Osmium impregnation of the Golgi apparatus. Am J Anat 1965;117:135-49.

3. Ghosh SK, Narayan RK. Anatomy of nervous system and emergence of neuroscience: a chronological journey across centuries. Morphologie 2020 Jun 10 [Epub]. http://dx.doi. org/10.1016/j.morpho.2020.05.005.

4. Fodstad H. The neuron theory. Stereotact Funct Neurosurg 2001;77:20-4.

5. Mazzarello P. [La struttura nascosta: la vita di Camillo Golgi]. Bologna: Cisalpino; 1996. Italian.

6. Dröscher A. Camillo Golgi and the discovery of the Golgi apparatus. Histochem Cell Biol 1998;109:425-30.

7. Calligaro A, Calligaro AL. The museum for the history of the university of Pavia and the birth of histology. J Hist Neurosci 1999;8:106-12.

8. Pannese E. The black reaction. Brain Res Bull 1996;41:343-9.

9. Bentivoglio M, Mazzarello P. The pathway to the cell and its organelles: one hundred years of the Golgi apparatus. Endeavour 1998;22:101-5.

10. Hierons R, Meyer A. The anatomy of the brain and nerves. Proc R Soc Med 1967;60:314.

11. Mazzarello P, Calligaro AL, Calligaro A. Giulio Bizzozero: a pioneer of cell biology. Nat Rev Mol Cell Biol 2001;2:776-81.

12. Mazzarello P, Garbarino C, Calligaro A. How Camillo Golgi became "the Golgi". FEBS Lett 2009;583:3732-7.

13. Langmoen IA, Apuzzo ML. The brain on itself: Nobel laureates and the history of fundamental nervous system function. Neurosurgery 2007;61:891-907; discussion 907-8.

14. Kruger L. The sensory neuron and the triumph of Camillo Golgi. Brain Res Rev 2007;55:406-10.

15. Pannese E. The contribution of Camillo Golgi to our understanding of the structure of the nervous system. Arch Ital Biol 2007;145:111-5.

16. De Carlos JA, Borrell J. A historical reflection of the contributions of Cajal and Golgi to the foundations of neuroscience. Brain Res Rev 2007;55:8-16.

17. Torres-Fernández O. [The Golgi silver impregnation method: commemorating the centennial of the Nobel Prize in medicine
(1906) shared by Camillo Golgi and Santiago Ramón y Cajal]. Biomedica 2006;26:498-508. Spanish.

18. Cani V, Mazzarello P. Golgi and Ranvier: from the black reaction to a theory of referred pain. Funct Neurol 2015;30:73-7.

19. Ghosh SK. Evolution of illustrations in anatomy: a study from the classical period in Europe to modern times. Anat Sci Educ 2015;8:175-88.

20. Guillery RW. Observations of synaptic structures: origins of the neuron doctrine and its current status. Philos Trans R Soc Lond B Biol Sci 2005;360:1281-307.

21. Golgi C. [Sulla struttura della sostanza grigia dell cervello', Gazz]. Med Lombarda 1873;33:224-46. Italian.

22. Golgi C. [Sulle alterazioni degli organi centrali nervosi in un caso di corea gesticolatoria associata ad alienazione mentale]. Riv Clin 1874;4:361-77. Italian.

23. Golgi C. [Sulla fina struttura dei bulbi olfattori: ricerche]. Reggio Emilia: S. Calderini; 1875. Italian.

24. Golgi C. Della terminazione dei nervi nei tendini e di Nuovo apparato nervosa terminale musculo-tendineo. Atti della settima reunione straordinaria della Societa Italiana di Scienze Naturali in Varese. Milano, Tipografia di Giuseppe Bernardoni 1878;272-275.

25. Golgi C. [Sulla struttura delle fibre nervosa midollate periferiche e centrali]. Arch Sci Med (Torino) 1880;4:221-46. Italian.

26. Golgi C. [Sui nervi dei tendini dell'uomo e di altri vertebrati e di un nuovo organo nervoso terminale musculo-tendineo]. Mem R Acad Sci Torino 1880;32:359-85. Italian.

27. Brabin BJ. Malaria's contribution to World War One- the unexpected adversary. Malar J 2014;13:497.

28. Ushkalov AF, Vikhert AM. [Morphology of the renal juxtaglomerular apparatus]. Arkh Patol 1972;34:3-17. Russian.

29. Barajas L. Anatomy of the juxtaglomerular apparatus. Am J Physiol 1979;237:F333-43.

30. Cowdry EV. Conservatism in cytological nomenclature. Anat Rec 1921;22:239-50.

31. Covell WP, Scott GH. An experimental study of the relation between granules stainable with neutral red and the Golgi apparatus in nerve cells. Anat Rec 1928;38:377-99.

32. Douglas SH. A note on the work of v. la valette St. George, the discoverer of the Golgi apparatus and mitochondria of modern cytology. J R Microsc Soc 1935;55:28-31.

33. Golgi C. [Di una minuta particolarità di struttura dell'epitelio della mucosa gastrica ed intestinale di alcuni vertebrati]. Boll Soc Med Chir Pavia 1909;24:1-22. Italian.

34. Yuste R. From the neuron doctrine to neural networks. Nat Rev Neurosci 2015;16:487-97.

35. Fodstad H, Kondziolka D, de Lotbinière A. The neuron doctrine, the mind, and the arctic. Neurosurgery 2000;47:1381-8; discussion 1388-9.

36. Jones EG. Golgi, Cajal and the neuron doctrine. J Hist Neurosci 1999;8:170-8.

37. De Carlos JA, Pedraza M. Santiago Ramón y Cajal: the Cajal Institute and the Spanish Histological School. Anat Rec (Hoboken) 2014;297:1785-802. 
38. Kruger L, Otis TS. Whither withered Golgi? A retrospective evaluation of reticularist and synaptic constructs. Brain Res Bull 2007;72:201-7.

39. Katz-Sidlow RJ. The formulation of the neuron doctrine: the Island of Cajal. Arch Neurol 1998;55:237-40.

40. Grant G. How the 1906 Nobel Prize in Physiology or Medicine was shared between Golgi and Cajal. Brain Res Rev 2007;55:490-8.

41. Chu NS. [Centennial of the nobel prize for Golgi and Cajal- founding of modern neuroscience and irony of discovery]. Acta Neurol Taiwan 2006;15:217-22. Chinese.

42. López-Muñoz F, Boya J, Alamo C. Neuron theory, the cornerstone of neuroscience, on the centenary of the Nobel Prize award to Santiago Ramón y Cajal. Brain Res Bull 2006;70:391405.

43. Tabassum R, Jeong NY, Chung HJ. Big data differential analysis of microglial cell responses in neurodegenerative diseases. Anat Cell Biol 2019;52:469-77. 